\title{
How Do Astrocytes Participate in Neural Plasticity?
}

\author{
Philip G. Haydon ${ }^{1}$ and Maiken Nedergaard ${ }^{2}$ \\ ${ }^{1}$ Department of Neuroscience, Tufts University School of Medicine, Boston, Massachusetts 02111 \\ ${ }^{2}$ Center for Translational Neuromedicine, Division of Glial Disease and Therapeutics, University of Rochester \\ Medical Center, Rochester, New York 14642 \\ Correspondence: philip.haydon@tufts.edu; Nedergaard@urmc.rochester.edu
}

\begin{abstract}
Work over the past 20 years has implicated electrically nonexcitable astrocytes in complex neural functions. Despite controversies, it is increasingly clear that many, if not all, neural processes involve astrocytes. This review critically examines past work to identify the commonalities among the many published studies of neuroglia signaling. Although several studies have shown that astrocytes can impact short-term and long-term synaptic plasticity, further work is required to determine the requirement for astrocytic $\mathrm{Ca}^{2+}$ and other second messengers in these processes. One of the roadblocks to the field advancing at a rapid pace has been technical. We predict that the novel experimental tools that have emerged in recent years will accelerate the field and likely disclose an entirely novel path of neuroglia signaling within the near future.
\end{abstract}

$T^{\mathrm{T}}$ he year 2014 represents the 20th anniversary of a pair of papers published by the writers that provided the first indication that astrocytes actively signal to neurons, and that these glial cells have the potential to be participants in the control of neural circuit function and behavior (Nedergaard 1994; Parpura et al. 1994). Although we have taken independent paths, we come together on this anniversary to discuss what we have learned since 1994, where we see the field progressing, and, finally, to discuss some key steps that we believe should be taken in the next decade to begin to further clarify the diverse roles that astrocytes play in brain function in health and disease.

Without knowledge of one another's work, we published a pair of papers that provided the first demonstration that physiological changes in astrocytes influence neurons: stimulated $\mathrm{Ca}^{2+}$ changes in astrocytes led to delayed $\mathrm{Ca}^{2+}$ responses in neurons (Nedergaard 1994; Parpura et al. 1994). To set the backdrop to these studies, this was a period of explosive growth in $\mathrm{Ca}^{2+}$ imaging that resulted from the availability of fluorescent $\mathrm{Ca}^{2+}$ indicators and sensitive cameras to permit low-light-level imaging of intracellular biochemistry. As a consequence, there had been several recently published studies revealing that astrocytes show $\mathrm{Ca}^{2+}$ elevations in response to mechanical contact or even to the addition of neurotransmitters, such as glutamate (Cornell-Bell et al. 1990). However, the functional downstream consequences were unknown. In our studies, which used a combina-

Editors: Ben A. Barres, Marc R. Freeman, and Beth Stevens

Additional Perspectives on Glia available at www.cshperspectives.org

Copyright (C) 2015 Cold Spring Harbor Laboratory Press; all rights reserved; doi: 10.1101/cshperspect.a020438

Cite this article as Cold Spring Harb Perspect Biol 2015;7:a020438 
P.G. Haydon and M. Nedergaard

tion of different stimuli-mechanical, optical, as well as a chemical transmitter bradykininwe were able to show a robust impact of the astrocytic $\mathrm{Ca}^{2+}$ signal on the adjacent neurons (Nedergaard 1994; Parpura et al. 1994). Despite differences in mechanistic conclusions, these papers stimulated revised thinking about roles of astrocytes in the brain-perhaps these glial cells were actively signaling, albeit on a slower time scale, to modulate neurons, circuits, and, ultimately, behavior.

The subsequent two decades have been spent examining the signaling of astrocytes to neurons in more intact systems. As a consequence of this work, it is clear that astrocytes play critical roles in actively modulating brain function, although we are still putting the pieces of the puzzle in place to understand where, when, and how this process occurs naturally in vivo and when dysfunction can lead to disorders of the brain.

The field has gone through an explosive growth that has consisted of several phases. Initially, there was the dish phase in which the potential of the astrocyte was revealed in cell culture. These studies were essential as they captured our imagination and stimulated new thinking; however, they were limited by the fact that the properties of astrocytes can be different in vitro and in vivo. Next, we had the in situ phase, in which we asked whether similar processes could be detected in situ in acutely isolated brain slices. Then we began asking about roles in vivo through $\mathrm{Ca}^{2+}$ imaging together with two-photon microscopy as well as with molecular genetic alterations to permit the inhibition and stimulation of astrocytes. Each of these phases has offered unique insights, challenges, and opportunities for the field.

Through all of these phases, an emergent picture is developing in which it is without doubt that astrocytes play important roles in vivo but that the mechanisms are so diverse and complex that an understanding is still to emerge.

Some of the major challenges that we have faced and continue to face include: What are the endogenous signals of these glial cells? How can we stimulate astrocytes in a physiologically relevant manner? How can we inhibit astrocytes to determine when they are needed for brain function? And last, but by no means least, how diverse are astrocytes?

We are still at the early days of understanding astrocytes, and patience regarding functional interpretation is required. We make this statement because there have been apparently contradictory conclusions drawn from different studies. The individual observations are important as they help provide a fuller picture of the biology of these complex cells. However, the jury still needs further evidence before definitive conclusions can be drawn. For example, a plethora of studies have shown that $\mathrm{Ca}^{2+}$ signals stimulate gliotransmission and the consequent modulation of neurons and synapses (see Table 1). A significant endogenous source of the $\mathrm{Ca}^{2+}$ signal of the astrocyte is from the $\mathrm{IP}_{3}$-sensitive $\mathrm{Ca}^{2+}$ store. Thus, when an $\mathrm{IP}_{3} \mathrm{R}_{2}$ knockout mouse was used and it was found to have no impact on synaptic transmission and plasticity (Agulhon et al. 2010), the field was rocked. We do not question the data of the study; instead, we believe this is an important piece of information that ultimately needs to be put in context. In contrast, additional studies have shown that $\mathrm{IP}_{3}$ receptors are important for other aspects of astrocyte-induced synaptic modulation. A more recent study has shown that, in addition to $\mathrm{Ca}^{2+}$ release from internal stores, the influx of $\mathrm{Ca}^{2+}$ through transient receptor potential (TRP) channels is important for gliotransmission (Shigetomi et al. 2013). Clearly, such influx sites were unlikely to have been affected by the $\mathrm{IP}_{3} \mathrm{R}_{2}$ knockout and were shown to regulate $\mathrm{D}$-serine release from the astrocyte. Another piece of the puzzle is added. Undoubtedly, there will be further twists and turns, but that is the joy of discovery, and it should be embraced.

We believe that it is also important to be constrained when discussing $\mathrm{Ca}^{2+}$ as there is not just one type of $\mathrm{Ca}^{2+}$ signal. For example, there are global $\mathrm{Ca}^{2+}$ signals in which large somatic $\mathrm{Ca}^{2+}$ elevations arise and that can propagate as slow waves between adjacent astrocytes in slices preparation. In vivo, astrocytes in awake mice display global $\mathrm{Ca}^{2+}$ increases that often simultaneously engaged most cells within the field of view. Isolated oscillatory cellular $\mathrm{Ca}^{2+}$ 
How Do Astrocytes Participate in Neural Plasticity

Table 1. Effect of $\mathrm{Ca}^{2+}$ signaling on excitatory or inhibitory potentials, slow inward current, synaptic failure, or neural bistability

\begin{tabular}{|c|c|c|c|c|}
\hline Preparation & $\begin{array}{l}\text { Method for inducing } \\
\text { astrocytic } \mathrm{Ca}^{2+} \text { signaling }\end{array}$ & $\begin{array}{l}\text { Change in the } \\
\text { frequency of EPSP } \\
\text { or IPSP }(\%)^{\mathrm{a}}\end{array}$ & $\begin{array}{l}\text { Duration of } \\
\text { modulation of } \\
\text { EPSP or IPSP }^{\text {a }}\end{array}$ & References \\
\hline $\begin{array}{l}\text { Hippocampal } \\
\text { cocultures }\end{array}$ & $\begin{array}{l}\text { Mechanical stimulation or } \\
\text { photolysis of caged } \mathrm{Ca}^{2+}\end{array}$ & - & $10-50 \mathrm{sec}$ & $\begin{array}{l}\text { Araque et al. } \\
1998\end{array}$ \\
\hline Retina & Mechanical stimulation & $\begin{array}{l}\text { Modulation of light- } \\
\text { induced neural } \\
\text { activity }\end{array}$ & $10-20 \mathrm{sec}$ & $\begin{array}{c}\text { Newman and } \\
\text { Zahs } 1998\end{array}$ \\
\hline $\begin{array}{l}\text { Frog } \\
\text { neuromuscular } \\
\text { junction }\end{array}$ & $\begin{array}{l}\text { Injection of GTP- } \gamma \mathrm{S} \text { in } \\
\text { perisynaptic Schwann cells }\end{array}$ & $\begin{array}{l}\text { Modulation of nerve- } \\
\text { evoked synaptic } \\
\text { responses }\end{array}$ & $\begin{array}{l}\text { For the duration } \\
\text { of the } \\
\text { recordings }\end{array}$ & Robitaille 1998 \\
\hline $\begin{array}{l}\text { Hippocampal } \\
\text { slices }\end{array}$ & Train of depolarization & $10 \%-30 \%$ & $\sim 60-120 \mathrm{sec}$ & $\begin{array}{l}\text { Jourdain et al. } \\
2007\end{array}$ \\
\hline $\begin{array}{l}\text { Hippocampal } \\
\text { slices }\end{array}$ & Photolysis & $\begin{array}{l}20 \%-30 \% \text { decrease } \\
\text { in synaptic failure }\end{array}$ & $50-60 \mathrm{sec}$ & $\begin{array}{l}\text { Perea and } \\
\quad \text { Araque } 2007\end{array}$ \\
\hline $\begin{array}{l}\text { Hippocampal } \\
\text { slices }\end{array}$ & Agonists (ATP, UTP, FMRF) & $\sim 20 \%-30 \%$ & $10-60 \mathrm{sec}$ & Wang et al. 2012a \\
\hline $\begin{array}{l}\text { Hippocampal } \\
\text { slices }\end{array}$ & Photolysis of caged $\mathrm{Ca}^{2+\mathrm{b}}$ & $\sim 30 \%$ & $10-60 \mathrm{sec}$ & Wang et al. 2013 \\
\hline \multicolumn{5}{|c|}{ Slow inward current } \\
\hline $\begin{array}{l}\text { Hippocampal } \\
\text { slices }\end{array}$ & $\begin{array}{l}\text { Agonist (DHPG) and } \\
\text { photolysis of caged } \mathrm{Ca}^{2+}\end{array}$ & Slow inward current & $\sim 20-50 \mathrm{sec}$ & Fellin et al. 2004 \\
\hline $\begin{array}{l}\text { Hippocampal } \\
\text { slices }\end{array}$ & Neuronal depolarization & Slow inward current & $\sim 50 \mathrm{sec}$ & $\begin{array}{l}\text { Navarrete and } \\
\text { Araque } 2008\end{array}$ \\
\hline \multicolumn{5}{|c|}{ Decrease in synaptic failure rate } \\
\hline $\begin{array}{l}\text { Hippocampal } \\
\text { slices }\end{array}$ & Train of depolarization & $\sim 20 \%-30 \%$ & $20 \mathrm{~min}$ & Kang et al. 1998 \\
\hline $\begin{array}{l}\text { Hippocampal } \\
\text { slices }\end{array}$ & Photolysis of caged $\mathrm{Ca}^{2+}$ & $\sim 20 \%-30 \%$ & $\sim 60 \mathrm{sec}$ & $\begin{array}{l}\text { Perea and } \\
\quad \text { Araque } 2007\end{array}$ \\
\hline $\begin{array}{l}\text { Hippocampal } \\
\text { slices }\end{array}$ & Agonists & $\sim 20 \%-30 \%$ & $10-60 \mathrm{sec}$ & Wang et al. $2012 \mathrm{a}$ \\
\hline $\begin{array}{l}\text { Hippocampal } \\
\text { slices }\end{array}$ & $\begin{array}{c}\text { Comparison of agonists and } \\
\text { photolysis of caged } \mathrm{Ca}^{2+}\end{array}$ & $\sim 20 \%-30 \%$ & $10-60 \mathrm{sec}$ & Wang et al. 2013 \\
\hline \multicolumn{5}{|l|}{ Bistability } \\
\hline Cortical slices & Trains of depolarization & $\begin{array}{l}\text { Upstate } \\
\text { synchronizations }\end{array}$ & - & $\begin{array}{l}\text { Poskanzer and } \\
\text { Yuste } 2011\end{array}$ \\
\hline Cerebellar slices & Agonists (ATP, UTP, FMRF) & $\begin{array}{l}\text { Increase in duration } \\
\text { of upstate }\end{array}$ & $40-60 \mathrm{sec}$ & $\begin{array}{l}\text { Wang et al. } \\
\text { 2012b }\end{array}$ \\
\hline
\end{tabular}

All of the studies included in the table show that the modulatory effect on neural activity is $\mathrm{Ca}^{2+}$-dependent (BAPTA loading, thapsigargin, and/or use of transgenic mice with deletion of $\mathrm{IP}_{3} \mathrm{R}_{2}$ receptors).

DHPG, dihydroxyphenylglycine; EPSP, excitatory postsynaptic potential; IPSP, inhibitory postsynaptic potential.

${ }^{a}$ For simplicity, EPSP and IPSP denote excitatory or inhibitory potentials or currents in both presence and absence of tetrodotoxin (TTX). Details can be found in the original papers.

${ }^{\mathrm{b}}$ The same study compared the effect of photolysis and agonist-induced astrocytic $\mathrm{Ca}^{2+}$ signaling and found that only photolysis, but not agonist exposure, induced changes in the frequency of EPSPs. 
P.G. Haydon and M. Nedergaard

signals can be restricted to one cell, and there are "spotty" $\mathrm{Ca}^{2+}$ signals that can be restricted to local microdomains (Shigetomi et al. 2013). It is possible, even likely, that each of these signals mediates different processes and more effort should focus on understanding the important functional distinction between each.

Other areas of interesting debate have concerned how gliotransmitters are released. Evidence exists for multiple mechanisms: exocytosis, anion transporters, and connexin hemichannels, to name a few. Significant evidence exists for each, and it is likely that all are used, although in different locales, and are recruited under differing conditions. A challenge is to perform precise experiments that allow the discrimination between each mechanism and to identify when each is recruited in physiology and/or pathology.

\section{$\mathrm{CA}^{2+}$-DEPENDENT GLIOTRANSMITTER RELEASE}

A wealth of studies over the past two decades has shown that astrocytes are active participants in synaptic transmission. Astrocytes provide not only metabolic support for hungry synapses, but also actively modulate synaptic strength. Work from multiple laboratories shows that astrocytes participate in synaptic transmission by releasing gliotransmitters that include glutamate, ATP, adenosine, or D-serine in slices. Many, although not all, of these studies have used brain slices prepared from juvenile rodent pups (reviewed in Araque et al. 1999; Nedergaard et al. 2003; Allen and Barres 2005) making it important to determine which of the observations are limited to postnatal development as opposed to physiology of mature systems. Progress in the field of neuroglia signaling has been so rapid in recent years that it requires us to take a step back and reflect on what the information generated by many groups actually tells us about the brain and how it functions.

Looking back at the literature on neuroglia signaling, it is clear that the most popular approach to studying the involvement of astrocytes in neural activity has been to record excitatory postsynaptic potentials (EPSP) or inhibitory postsynaptic potentials (IPSP) (Fig. 1). These studies have often used whole-cell patching combined with selective simulation of astrocytic $\mathrm{Ca}^{2+}$ signaling. Such analysis has shown that astrocytic $\mathrm{Ca}^{2+}$ signaling can trigger an increase in EPSP or IPSP frequencies and, in more selected cases, also increase the amplitudes of excitatory potentials. For example, in one study, mechanical-induced astrocytic $\mathrm{Ca}^{2+}$ signaling increased the frequency of EPSPs and IPSPs by $20 \%-50 \%$ in cocultures of astrocytes and neurons (Araque et al. 1998). Similarly, photolysis of caged $\mathrm{IP}_{3}$ triggered a transient increase in the EPSC frequency in the range of $20 \%-60 \%$ in hippocampal slices from 10- to 15-d-old mouse pups (Fiacco and McCarthy 2004). It is a typical finding among these and later studies on neuroglia signaling that the potentiation is transient and ceases after 20-60 sec (Table 1). One line of work has instead detected slow inward current mediated by extrasynaptic $N$-methyl-Daspartate receptors (NMDARs) (NR2B) (Fellin et al. 2004). Another, albeit less popular, approach has been to evaluate the effect of astrocytic $\mathrm{Ca}^{2+}$ signaling on synapses with a high rate of failures. These studies are technically more difficult as they are based on either double patching of synaptically coupled neurons (Kang et al. 1998) or single patching combined with minimal stimulation (Perea and Araque 2007; Navarrete and Araque 2008; Wang et al. 2012a). The analysis from several laboratories shows that stimulation of $\mathrm{Ca}^{2+}$ signaling can reduce synaptic failure by $10 \%-30 \%$, but the effect is short lived and does not persist beyond a few minutes (Table 1). Finally, in more recent papers, bistability of neural membrane potential has also been shown to be affected by stimulation of either cortical astrocytes (Poskanzer and Yuste 2011) or Bergmann glia (Wang et al. $2012 b)$. In both cases, $\mathrm{Ca}^{2+}$ signaling resulted in short-lived $(<1 \mathrm{~min})$ changes in the stereotypical pattern of neuronal up and down states (Table 1). It is important to note that the modulatory effects of astrocytes are relatively modest and the conditions need to be optimized, including consistency of time of the day in which data are collected (see later discussion). It is therefore not surprising that several studies 


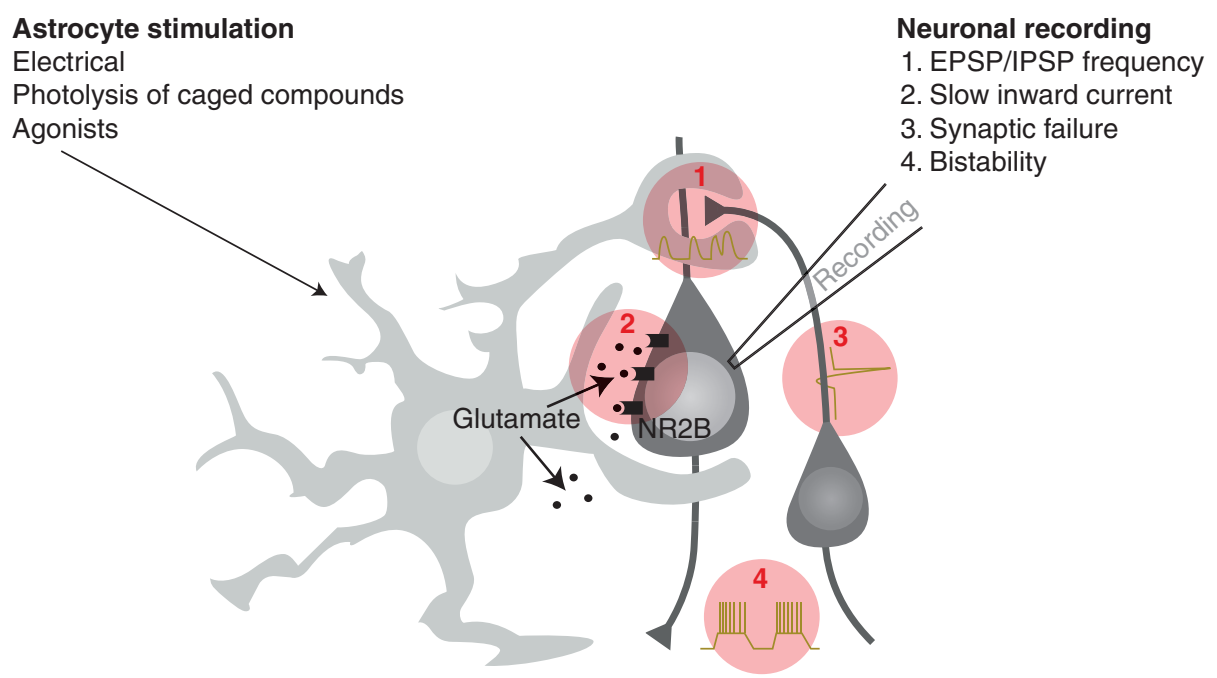

Figure 1. Common approaches to study astrocyte-to-neuron signaling. Astrocytic $\mathrm{Ca}^{2+}$ signaling is evoked by either photolysis of caged compounds $\left(\mathrm{Ca}^{2+}\right.$ or $\left.\mathrm{IP}_{3}\right)$, train of depolarizations (electrical), or agonist application. The effect of astrocytic $\mathrm{Ca}^{2+}$ signaling is typically monitored by whole-cell patching of a nearby neuron. Most studies have recorded changes in either (1) the frequencies of EPSP/IPSP, (2) NR2B-mediated slow inward currents, (3) rate of synaptic failure in synaptically couple neurons, or (4) bistability of neuronal membrane potential. Recordings before, during, and after induction of astrocytic $\mathrm{Ca}^{2+}$ signaling is used to evaluate the potency by which astrocytes modulate neuronal activity. Table 1 compares the data from the many groups using these approaches.

have failed to detect astrocytic regulation of synaptic transmission.

Thus, work from multiple independent laboratories shows that astrocytes can transiently modulate synaptic transmission in slices prepared from young pups via a $\mathrm{Ca}^{2+}$-dependent pathway. One important take-home message from Table 1 is that the impact of astrocytes is limited to a timescale of tens of seconds. Astrocytic $\mathrm{Ca}^{2+}$ signaling, whether evoked by electrical stimulation, photolysis of caged compounds, or agonists, only evokes an $\sim 10$ - to 60 -sec-lasting modulation in the activity of nearby neurons. The similarities of the observations listed in Table 1 are remarkable considering that different approaches were used to both stimulate astrocytes and detect effects in neighboring neurons. This suggests that mobilization of astrocytic $\mathrm{Ca}^{2+}$ stores and subsequent increases in cytosolic $\mathrm{Ca}^{2+}$ may trigger a stereotypical response that can be detected as either changes in the frequency of synaptic potentials, as slow inward currents, changes in neuronal bistability of membrane potential, or as a decrease in extra- cellular $\mathrm{K}^{+}$concentrations. Other lines of work indicate that $\mathrm{Ca}^{2+}$ increases are linked to a minor hyperpolarization $(2-4 \mathrm{mV})$ rather than depolarizations of astrocytic membrane potential, as well as an increase in glycogenolysis. It is important to extend these observations into a full description of what intracellular processes are activated in astrocytes on increases in cytosolic $\mathrm{Ca}^{2+}$. The difficulties in developing a comprehensive understanding is that neural output measures in the past have represented the principal tool for detecting astrocytic responses to $\mathrm{Ca}^{2+}$ increases. Another important question that we address below is whether the modulation of the synapse is the sole, or primary, target of gliotransmission and whether astrocytes exert neuromodulation over different timescales.

\section{THE IMPORTANCE OF EXTRACELLULAR $\mathrm{K}^{+}$IN SETTING THE THRESHOLDS FOR GENERATION OF ACTION POTENTIALS}

The foundation for neural activity is not limited to synaptic transmission. The ability of neurons 
P.G. Haydon and M. Nedergaard

to propagate action potentials forms the basis for all complex neural functions. What if astrocytes control or regulate the ability of neurons to generate action potentials? Modulation of the threshold by which action potentials are generated could potentially position astrocytes into a far more active role than previously recognized. The two key determinants for generation of action potentials are the resting neuronal membrane potential and the threshold for activation of voltage-gated sodium channels. Voltage-gated $\mathrm{Na}^{+}$channels generate the steep depolarization characteristic of action potentials in neurons when the membrane potential reaches $-55 \mathrm{mV}$ or lower (Hounsgaard and Nicholson 1983). Thus, the voltage gap between the resting membrane potential and the threshold for activation of $\mathrm{Na}^{+}$channels is an important factor determining the excitability of neural networks. According to the classical or "textbook" definition, it is the relative balance between excitatory and inhibitory input or the frequencies of EPSPs and IPSPs that determines when the membrane potential reaches the magical threshold of $-55 \mathrm{mV}$ at which an action potential is triggered. It is often forgotten that the resting membrane potential of neurons is highly sensitive to changes in extracellular $\mathrm{K}^{+}$. Even minor increases or decreases in $\mathrm{K}^{+}$will enhance or reduce neural excitability by altering the gap between the resting membrane potential and activation of voltage-gated $\mathrm{Na}^{+}$channels (Wang et al. 2012a). In slices, simply increasing both extracellular $\mathrm{K}^{+}$leads to epileptiform activity (Traynelis and Dingledine 1988), and local cortical application of $\mathrm{K}^{+}$triggers myoclonic seizures within minutes in awake wild-type mice (Rangroo Thrane et al. 2013). Not unexpectedly, the central nervous system (CNS) has invested considerable effort into maintaining extracellular $\mathrm{K}^{+}$in a tightly controlled range of 3.5-4.0 mM. For example, the permeability of the blood-brain barrier $(\mathrm{BBB})$ to $\mathrm{K}^{+}$is low, and a bolus injection of $\mathrm{K}^{+}$injected into blood does not change extracellular $\mathrm{K}^{+}$concentrations in the cortex (Hansen et al. 1977). Astrocytes were identified more than 50 years ago as the primary cell type responsible for $\mathrm{K}^{+}$buffering. Work by the Leif Hertz group (Hertz 1965) showed that astrocytes are specialized for rapid uptake of $\mathrm{K}^{+}$. Later, Kuffler showed that astrocytes are highly $\mathrm{K}^{+}$permeable (Orkand et al. 1966). These observations, as well as other more recent studies, have led to the concept that astrocytes are the cell type chiefly responsible for buffering the increases in $\mathrm{K}^{+}$that occur during neural firing. Some controversies have existed with regard to how astrocytes actually buffer excess $\mathrm{K}^{+}$. Multiple pathways, including Kir4.1, NKCCl, and the $\mathrm{Na}^{+}, \mathrm{K}^{+}$ATPase, were originally implicated in $\mathrm{K}^{+}$buffering (Walz 2000; D’Ambrosio et al. 2002), but later studies have refined the concepts by showing that increases in extracellular $\mathrm{K}^{+}$are primarily eliminated by astrocytic $\mathrm{K}^{+}$uptake via the $\mathrm{Na}^{+}, \mathrm{K}^{+}$ ATPase (Wallraff et al. 2006; Seifert et al. 2009) . Kir4.1 is important for setting the resting membrane potential, but appears to play a minor role, if any, in buffering local increases in $\mathrm{K}^{+}$ (Chever et al. 2010). The NKCCl cotransporter is expressed at low levels by astrocytes in the adult rodent brain and is therefore unlikely to be implicated in $\mathrm{K}^{+}$buffering (Larsen et al. 2014). Thus, astrocytes are chiefly responsible for $\mathrm{K}^{+}$buffering via the $\mathrm{Na}^{+}, \mathrm{K}^{+}$ATPase, and, thereby, are similarly responsible for stabilizing neural membrane potential (Larsen et al. 2014)

\section{$\mathrm{CA}^{2+}$-DEPENDENT $\mathrm{K}^{+}$UPTAKE}

In addition to uptake of excess $\mathrm{K}^{+}$, recent work shows that astrocytes also are engaged in active control of resting extracellular concentrations of $\mathrm{K}^{+}$. Analyses in vitro, in hippocampal slices, and in vivo show that astrocytic $\mathrm{Ca}^{2+}$ signaling leads to the rapid uptake of $\mathrm{K}^{+}$and a transient lowering of extracellular $\mathrm{K}^{+}$(Wang et al. 2012a). Pharmacological analysis indicates that $\mathrm{Ca}^{2+}$-mediated $\mathrm{K}^{+}$uptake is driven by the $\mathrm{Na}^{+}, \mathrm{K}^{+}$ATPase and is dependent on the influx of $\mathrm{Na}^{+}$facilitated by the $\mathrm{Na}^{+}, \mathrm{Ca}^{2+}$ exchanger (NXC) (Wang et al. 2012a). The intracellular concentration of $\mathrm{Na}^{+}$ in many cells, including astrocytes, is rate limiting for the activity of the $\mathrm{Na}^{+}, \mathrm{K}^{+}$ATPase (Pellerin and Magistretti 1997; Lupfert et al. 2001). Thus, increases in $\mathrm{Na}^{+}$activate the $\mathrm{Na}^{+}, \mathrm{K}^{+}$ ATPase and, consequently, lower the levels of extracellular $\mathrm{K}^{+}$. $\mathrm{Ca}^{2+}$-regulated $\mathrm{K}^{+}$uptake has 
been shown to decrease the frequency of EPSPs at baseline in a time frame concomitant with a reduction in the rate of synaptic failures (Wang et al. 2012a). The net result is that astrocytes via active uptake of $\mathrm{K}^{+}$reduce baseline EPSP activity (noise), while enhancing the precision of signal transmission. In other words, astrocytic $\mathrm{Ca}^{2+}$ signaling increases the signal-to-noise ratio of neural processing. $\mathrm{Ca}^{2+}$-mediated $\mathrm{K}^{+}$uptake endows astrocytes with a simple yet powerful tool for rapid and widespread manipulation of neural networks (Wang et al. 2012a). However, similar to gliotransmitter release, active $\mathrm{K}^{+}$uptake is transient and extracellular $\mathrm{K}^{+}$returns to baseline levels within $\sim 60 \mathrm{sec}$.

\section{LONG-TERM CHANGES IN NEURAL NETWORKS AND THE ROLE OF ASTROCYTES}

Other lines of work have assessed the role of astrocytes in longer-lasting plasticity or more specifically in hippocampal long-term potentiation (LTP). Perhaps the most contentious area has surrounded the influence of astrocytes in the modulation of LTP in brain slice preparations. At this time, it is not clear why different results have been obtained; however, possibilities include different stimulus conditions, temperature, and age of preparations. Rather than debating pros and cons of each study, we simply report the results of a few. In most of these studies, LTP was triggered by high-frequency stimulation (HFS), and the effects of genetic or pharmacological manipulation of astrocytes assessed in parallel. In the first study of astrocytes in LTP, dominant-negative inhibition of vesicular release (soluble NSF attachment protein receptors [SNARE]) under the astrocyte-specific promoter, glial fibrillary acidic protein (GFAP), lowered baseline adenosine concentration (Pascual et al. 2005), which leads to a long-term change in postsynaptic NMDAR trafficking (Clasadonte et al. 2013), and, as a consequence, leads to a change in modulation of the magnitude of NMDAR-dependent LTP. In another study, Dserine release from astrocytes was shown to be critical for NMDAR-dependent LTP (Henneberger et al. 2010). Another group showed that engraftment of human astrocytes lowered the threshold for induction of LTP in the murine hippocampus by increasing AMPA receptor recruitment in response to HFS. This effect was shown to be mediated, at least in part, by release of tumor necrosis factor (TNF)- $\alpha$ (Han et al. 2013). Glia-derived TNF- $\alpha$ drives insertion of AMPA receptors in the postsynaptic membrane (Stellwagen and Malenka 2006). Combined, these studies show that astrocytic-derived neuromodulators, including adenosine, D-serine, or $\mathrm{TNF}-\alpha$ alter neuronal responsiveness to HFS, resulting in long-lasting changes in neural excitability. It is worth noting that neither the control of adenosine nor TNF- $\alpha$ reports included astrocytic $\mathrm{Ca}^{2+}$ signaling as a key step in longterm neural plasticity. In contrast, significant evidence supports a role for astrocytic $\mathrm{Ca}^{2+}$ signaling in the regulation of extracellular $\mathrm{D}$-serine. These studies raise the interesting potential that there is one or more $\mathrm{Ca}^{2+}$-independent glial pathway that regulates neuroglial coupling and deserves further attention. This is a consideration we return to later when we discuss time of day and vigilance state-dependent regulation of gliotransmission.

Thus, looking back on reports published over the last several decades, it is clear that single episodes of astrocytic $\mathrm{Ca}^{2+}$ signaling exert a transient effect on synaptic transmission and that more sustained effects, either mediated via modulation of receptor trafficking or excitability, may act independent of $\mathrm{Ca}^{2+}$ excitability. This conclusion is supported by other lines of work showing that astrocytes are instrumental for synapse formation, maintenance, and elimination (Ullian et al. 2004; Allen and Barres 2005; Chung and Barres 2012).

\section{IN VIVO STUDIES}

To develop a framework for how astrocytes participate in complex neural processes, it is necessary to include in vivo studies. Does the analysis of live animals contain the information that will decipher how astrocytes contribute to neural function beyond their metabolic and homeostatic functions? Maybe. Several laboratories have studied astrocytic $\mathrm{Ca}^{2+}$ signaling in 
anesthetized or awake mice after loading the exposed cortex with fluorescent $\mathrm{Ca}^{2+}$ indicators. The most popular approaches have been to characterize astrocytic $\mathrm{Ca}^{2+}$ signaling evoked by sensory input, including whisker (Wang et al. 2006), visual (Schummers et al. 2008), or olfactory stimulation (Gurden et al. 2006). Other groups have studied astrocytic $\mathrm{Ca}^{2+}$ signaling during locomotion in awake animals (Dombeck et al. 2007; Hoogland et al. 2009; Nimmerjahn et al. 2009). So what have they found? Two main findings have so far emerged from these studies: (1) Astrocytic $\mathrm{Ca}^{2+}$ signals are coordinated and displayed as widespread synchronous $\mathrm{Ca}^{2+}$ increases that engage essentially all astrocytes within the field of view (typically $20-80$ cells across a $200-$ to $600-\mu \mathrm{m}$-wide field). Widespread synchronized $\mathrm{Ca}^{2+}$ increases are a consistent finding across many laboratories in in vivo preparations, but surprisingly, widespread synchronized $\mathrm{Ca}^{2+}$ signaling has never been observed in slices. Pathological conditions, such as acute ammonia toxicity, lead to a disappearance of global astrocytic $\mathrm{Ca}^{2+}$ increases, which are replaced with oscillatory increases of $\mathrm{Ca}^{2+}$ in single astrocytes (Rangroo Thrane et al. 2013). Similar observations have been made in more chronic disease states, such as mouse models of Alzheimer's disease in which astrocytes display abnormal oscillatory increases in $\mathrm{Ca}^{2+}$ (Takano et al. 2007; Kuchibhotla et al. 2009). (2) Astrocytes respond slowly to sensory stimulation with $\mathrm{Ca}^{2+}$ increases that first peak 3-10 sec after initiating the stimulation (Wang et al. 2009). The slow engagement of astrocytes in response to sensory stimulation is also a general phenomenon observed across different laboratories and corresponding to the slow speed at which astrocytic $\mathrm{Ca}^{2+}$ signaling is triggered in acute slices. A recent study based on a clever analysis of staggered imaging processing found that astrocytes also may display very fast $\mathrm{Ca}^{2+}$ transients, which peak within milliseconds after whisker stimulation (Lind et al. 2013). This observation is interesting but awaits confirmation from other groups. Notably, anesthesia has been shown to potently dampen the spontaneous widespread astrocytic $\mathrm{Ca}^{2+}$ signal, suggesting that mediators of wakefulness, including catecholamines, may play a role in spontaneous astrocytic $\mathrm{Ca}^{2+}$ signaling (Thrane et al. 2012).

Of note, the original in vivo studies attributed neuroglia $\mathrm{Ca}^{2+}$ signaling to activation of astrocytic metabotropic glutamate (mGlu) receptors by synaptic release of glutamate (Gurden et al. 2006; Wang et al. 2006; Schummers et al. 2008); glutamate acting as a mediator of neuroglia signaling has later been challenged by the finding that adult cortical and hippocampal astrocytes have significantly reduced expression of Gq-linked mGlu receptors and that mGlu receptor agonists only trigger astrocytic $\mathrm{Ca}^{2+}$ signaling during early development stages (before $3 \mathrm{wk}$ of age) (Sun et al. 2013). Because mGlu receptors are expressed by excitatory neurons, it is possible that the mGlu receptor agonists directly interfered with local transmission, but more studies are obviously needed. By comparing in vivo studies to observation in slices, it is clear that astrocytic $\mathrm{Ca}^{2+}$ signaling in intact adult brain and in acute slice preparations from young pups differ fundamentally with regard to both spatial extension and mode of initiation.

\section{NEUROMODULATORS AS A KEY MEDIATOR OF ASTROCYTIC $\mathrm{CA}^{2+}$ SIGNALING IN AWAKE MICE}

More recent observations point to the novel concept that both spontaneous and evoked astrocytic $\mathrm{Ca}^{2+}$ signaling are mediated by norepinephrine in response to locus coeruleus (LC) activation in awake mice. Direct stimulation of LC triggers coordinated and synchronous astrocytic $\mathrm{Ca}^{2+}$ signaling similar to spontaneous and evoked $\mathrm{Ca}^{2+}$ signaling (Bekar et al. 2008b; Ding et al. 2013). LC is the sole source of norepinephrine in forebrain. LC is located in pons, and LC neurons extend highly branched unmyelinated projections that form a large number of varicosities containing norepinephrine-containing vesicles (Levitt and Moore 1978). Less than $10 \%$ of these varicosities can be characterized as conventional synapses apposed to a postsynaptic membrane (Cohen et al. 1997). The remainder of these varicosities form open synapses in which norepinephrine is released broadly 
into the interstitial space. LC varicosities have been shown to be present in highest density close to blood vessels, but are also often apposed to axons, dendrites, and glial processes (Paspalas and Papadopoulos 1996; Cohen et al. 1997) The $\alpha 1$ receptor antagonist, prazosin, effectively suppresses both evoked and spontaneous astrocytic $\mathrm{Ca}^{2+}$ signaling (Ding et al. 2013). A recent beautiful study added additional support to the idea that $\alpha 1$ adrenergic receptors are primarily responsible for spontaneous astrocytic $\mathrm{Ca}^{2+}$ signaling in awake mice, and extended the concept by proposing that norepinephrine shifts the gain of astrocyte networks according to behavioral state, enabling astrocytes to respond to local changes in neuronal activity (Paukert et al. 2014). In retrospect, it is possible that prior reports on sensory-induced $\mathrm{Ca}^{2+}$ signaling, in fact, represented norepinephrine release in response to a salient stimulation. For example, arousal evoked by an unexpected sensory stimulation, such as sudden whisker stimulation, is associated with the concerted release of multiple neuromodulators. An analysis of the success rate and delay of whisker stimulation suggested that induced astrocytic $\mathrm{Ca}^{2+}$ signaling is indeed mediated by norepinephrine release (Ding et al. 2013). Moving from whisker stimulation to a classical startle response triggered by a puff of air to the eye and tail increased the success rate and variability, as well as reduced the delay of stimulation-induced astrocytic $\mathrm{Ca}^{2+}$ signaling. These observations support the idea that whisker-induced $\mathrm{Ca}^{2+}$ signaling is a response to arousal rather than to the local increase in excitatory transmission (Ding et al. 2013). The slow and more widespread responses of astrocytes fit well with such an action of neuromodulators (Bekar et al. 2008b).

\section{DO NEUROMODULATORS ACT THROUGH ASTROCYTES TO EVOKE LONG-LASTING PLASTICITY OF NEURAL CIRCUITS?}

In regard to this question, work performed in both slices and in vivo has shown that when combined with sensory glutamatergic input, cholinergic signaling can trigger long-lasting changes in synaptic strength (LTP). Findings from three independent laboratories show that mice in which astrocytes cannot mobilize cytosolic $\mathrm{Ca}^{2+}$ stores $\left(\mathrm{IP}_{3} \mathrm{R}_{2}\right.$ knockout mice) failed to develop long-term enhancement of excitatory transmission in response to combined stimulation of cholinergic and sensory inputs. In these studies, sensory input (whisker [Takata et al. 2011], visual stimulation [Chen et al. 2012], or tail pinch [Navarrete et al. 2012]) in combination with stimulation of nucleus basalis or cholinergic fibers resulted in a sustained potentiation of excitatory transmission. Thus, emerging evidence suggests that neuromodulators may not only be responsible for spontaneous and evoked astrocytic $\mathrm{Ca}^{2+}$ signaling in awake mice, but also for long-term neural plasticity (Parpura and Verkhratsky 2012).

Astrocytes express Gq-linked, as well as Giand Gs-linked metabotropic receptors that are activated by norepinephrine, acetylcholine, serotonin, and likely other neuromodulators (Hertz et al. 2004; Verkhratsky et al. 2012). One of the characteristics of neuromodulators is that they typically target multiple cells via volume transmission and diffusion across considerable distances before receptor binding (Callado and Stamford 2000; Cragg et al. 2001). Another typical feature of neuromodulators is that they act in a slow time frame of seconds, typically affecting baseline neuronal activity rather than mediating specific responses (Izumi and Zorumski 1999; Huang et al. 2012). In fact, a rich literature suggests that neuromodulators are potent modulators of long-term synaptic plasticity and involved in both LTP and longterm depression (LTD) (Brocher et al. 1992; Otmakhova and Lisman 1996; Katsuki et al. 1997). This raises the question as to whether astrocytic $\mathrm{Ca}^{2+}$ is a key intermediary of the effect of neuromodulators. The widespread and slow mode of action certainly is shared between astrocytes and neuromodulators. The observation that anesthesia potently inhibits spontaneous astrocytic $\mathrm{Ca}^{2+}$ signaling (Thrane et al. 2012) is consistent with other observations that anesthesia potently suppresses the activity of both LC and nucleus basalis (Laalou et al. 2008; Bekar et al. 2012). 
P.G. Haydon and M. Nedergaard

\section{SLEEP, AROUSAL, AND VIGILANCE}

The observation of widespread astrocytic $\mathrm{Ca}^{2+}$ signals in vivo together with the ability of norepinephrine to "gate" these glial $\mathrm{Ca}^{2+}$ signals raises the intriguing potential that the astrocyte could mediate long-term modulation of selected circuits to promote different behavioral states. This notion is supported by in vivo studies that used molecular genetics targeted to the astrocyte and showed that astrocytes modulate sleep homeostasis (Halassa et al. 2009; Blutstein and Haydon 2013). Sleep is controlled by at least two substantial processes: the circadian oscillator and the sleep homeostat. The process of sleep homeostasis regulates the daily pressure to sleep and homeostatic responses to sleep deprivation. When dominant-negative $(\mathrm{dn})$ SNARE is expressed in astrocytes, under the control of the GFAP promoter, sleep homeostasis is impaired. Pharmacological and molecular genetic studies have shown that this is mediated by adenosine, which accumulates from an astrocytic source during wakefulness that acts through neuronal A1R to mediate these effects. Whole-cell pyramidal neuron recordings in vivo as well as local field potential recordings showed that this glial manipulation leads to a sustained change in the cortical slow oscillations (up and down states) that underlie slow wave activity of nonrapid eye movement (NREM) sleep.

These slow oscillations critically depend on the expression of neuronal NMDARs. Because astrocytic adenosine is known to modulate neuronal NMDAR trafficking and, consequently, synaptic NMDAR-mediated currents, this pathway provides the opportunity for the astrocyte to cause a sustained modulation of a neuronal circuit that underlies behavioral states-sleep and wakefulness. One caution regarding use of the GFAP-driven dnSNARE expression is that the selective expression by astrocytes versus other cell types has not been proven beyond the coexpression of enhanced green fluorescent protein (EGFP) and LacZ reporter genes. Because the genes for dnSNARE, LacZ, and EGFP were injected as independent genes when the transgenic mouse was generated, a valid critique might be that neither LacZ nor EGFP necessarily reflect dnSNARE expression (Pascual et al. 2005). How- ever, because the expression of dnSNARE was directly monitored in mixed cultures and only found to be present in astrocytes, such a concern is mitigated.

These studies prompted us to ask whether there might be time-of-day differences in the "state" of a brain slice given the importance of the astrocyte in the control of sleep homeostasis. To address this question, slices were isolated from mice at 4-h intervals during the 24-h day as well as from mice that had been sleep deprived. Astrocyte-derived adenosine was assessed using biosensors, as well as pharmacological enhancement of fEPSPs (brain slice) and local field potentials (in vivo) in response to the A1R antagonist CPT (Schmitt et al. 2012). Results of each of these three approaches were qualitatively in accordance with one another. Surprisingly, we observed differences in extracellular adenosine levels in accordance with the vigilance state of the animal. For example, if animals were euthanized and slices cut at the end of the dark phase (subjective daytime), then adenosine was elevated, whereas if slices were obtained during the light phase (subjective nighttime), adenosine levels were reduced. Moreover, this effect was mediated by the behavioral state because, when mice were sleep-deprived before isolating slices, we found that adenosine was elevated in comparison to the level recorded in slices prepared at the same time from undisturbed mice.

These studies provide several insights and raise many questions about the astrocyte and brain state. First, it becomes extremely important to document animal state and time of day that slices are obtained to allow comparisons of data between laboratories. Second, most animal facilities are maintained on a light cycle that corresponds with the animal technician's light cycle. However, because mice are nocturnal, this means we are often studying mice when they would normally be sleeping. Third, many of us study processes, such as plasticity and learning and memory, yet we are taking samples at a time when the brain (and the astrocyte) is in sleep mode. Do the data correspond to what would be obtained if studied during the dark phase? Are we missing astrocyte-mediated processes by studying brain samples during the light phase? 
An additional question that arises is how does the astrocyte and a brain slice have a memory of the time of day and state (e.g., sleep derived) that the animal was euthanized? Presumably, there is little neural activity in a brain slice that could be driving different amounts of glialderived adenosine. Could there be sustained behavioral state-dependent changes in astrocytic $\mathrm{Ca}^{2+}$ signals that are maintained in the dish? We doubt it. We are left to ponder the possibility, as discussed earlier, that there are many $\mathrm{Ca}^{2+}-\mathrm{in}-$ dependent signals that regulate the astrocytic compartment that have gone unexplored to date, which might account for these differences. For example, the recently described glymphatic system-a macroscopic clearance system-is primarily active in the sleeping animals (Xie et al. 2013). Does astrocytic $\mathrm{Ca}^{2+}$ signaling suppress glymphatic activity? Indirect evidence supports that idea. Astrocytic $\mathrm{Ca}^{2+}$ signaling is primarily induced by activation of astrocytic $\alpha 1$ adrenergic receptors in awake-behaving mice (Ding et al. 2013). Because antagonists of adrenergic receptors inhibit astrocytic $\mathrm{Ca}^{2+}$ signaling (Ding et al, 2013) and enhance glymphatic activity in awake mice (Xie et al. 2013), it is possible that astrocytic $\mathrm{Ca}^{2+}$ signaling regulates the water and solute transport that drives glymphatic exchange of cerebrospinal fluid (CSF) and interstitial fluid. Additional studies are needed to prove this point, but it is clear that astrocytes depend heavily on the water channel AQP4, because global or conditional deletion of AQP4 reduces glymphatic activity by $\sim 60 \%$ (Iliff et al. 2012).

\section{IS IT POSSIBLE TO PUT IT ALL TOGETHER?}

Taking a step back, one may conclude that analysis of neuroglia signaling in slice preparation in many ways does not reflect in vivo observations. Slices have traditionally been prepared from young rodent brains in which neither astrocytic nor neuromodulator signaling are mature (Takano et al. 2014). This has been a necessity because fluorescent $\mathrm{Ca}^{2+}$ indicators cannot be loaded in slices prepared from older animals (Nedergaard and Verkhratsky 2012). Approaches to stimulate astrocytes (or neurons) in slices also differ fundamentally from those used to assess operational transmission of sensory input in the intact brain. High-frequency stimulation triggers artificial ATP release (Bekar et al. 2008a), and uncaging of caged $\mathrm{Ca}^{2+}$ does not mimic receptor-mediated events and has fundamentally different impacts on neural activity (Wang et al. 2013). Because astrocytes do not express any receptors that are not expressed by neurons or other cell types in the CNS, it has not been possible to use a selective agonist to activate $\mathrm{Ca}^{2+}$ signaling without affecting other cell types, including neurons. The use of transgenic mice expressing Mrg1A receptors, which are normally not expressed in the forebrain, has been criticized because it has not been established whether the Mrg1A receptors can activate physiologically relevant intracellular signaling pathways (Agulhon et al. 2010). Another problem with slices is that astrocytes almost immediately undergo a classical sign of reactive gliosis with expression of the developmental marker nestin, increases in GFAP, and mislocation of AQP4 (Takano et al. 2014). Astrocytes in the surface area of slices also rapidly lose their fine perisynaptic processes and may not support synaptic function optimally (Takano et al. 2014). In vivo preparations are also subjected to artifacts, including reduced capillary perfusion, anesthesia, microglial cell activation, and more (Xu et al. 2007).

All of these caveats might give the impression that it will be impossible to experimentally decode the roles of astrocytes in brain function. It is not our intention to cast a shadow of despair by making these comments; rather, we wish to point out some of the areas of caution that need to be exerted in interpreting past studies and in the design of future experiments. What is clear is that given the sensitivity of the astrocyte to age, time of day, anesthesia, and injury, great caution must be taken to design interpretable studies. To assist in this regard, considerable emphasis on the development of new astrocyte-specific molecular genetic manipulations is needed so that, when possible, observations and manipulations can be performed in intact, adult specimens. Toward this goal, genetically encoded $\mathrm{Ca}^{2+}$ indicators, such as GCam3-6, are expected to revolutionize our 
view on astrocytic involvement in cortical function. Additionally, mice expressing indicators of glucose and second messenger pathways beyond $\mathrm{IP}_{3} / \mathrm{Ca}^{2+}$ will become invaluable. For example, astrocytes express high levels of mGluR3, but we do not understand the functional consequences of activation of this Gi-coupled receptor. Current in vivo imaging studies have been focused on observing $\mathrm{Ca}^{2+}$ signals in response to sensory stimuli. Perhaps there are dramatic changes in intracellular cyclic adenosine monophosphate (cAMP) dynamics caused by glutamatergic activation of astrocytic mGluR3.

In addition to the development of models based on existing concepts and knowledge, a new opportunity awaits us in which we can use the human genetics and genome-wide association studies (GWAS) combined with existing mouse astrocyte gene expression databases to identify new targets for experimental intervention. For example, in a recent human autopsy study of patients suffering from major depressive and bipolar disorder, $G$ protein-coupled receptors were identified in which expression was changed in these patients. By referencing the mouse astrocyte databases, these receptors are highly enriched in astrocytes. For example, the orphan GPCR GPRC5B is highly enriched in astrocytes and is down-regulated in tissue from patients with major depressive disorder (MDD) and up-regulated in patients with bipolar disorder (Tomita et al. 2013). A GPRC5 knockout mouse has been generated and shows significant behavioral deficits (Sano et al. 2011). Whether such deficits arise from alterations in astrocytic signaling remains to be determined, but it will be intriguing to unravel given the potential links between this receptor and psychiatric disorders.

As we begin to decipher astroglial function, it will be important to turn to disorders of the nervous system to ask when and how the astrocyte contributes to the many societal burdens of psychiatric and neurological disorders of the brain. Although it is difficult to predict which of these disorders will have as a primary etiology an astroglial malfunction, it is of immediate interest to examine disorders with a sleep comorbidity. Studies from both of our laboratories have highlighted the importance of the astrocyte in sleep-related processes. On the one hand, the astrocyte modulates sleep homeostasis, and, on the other hand, this glial cell plays an important role in the clearance of amyloid $\beta$ from the brain during sleep. Could disorders in the astrocyte contribute to disorders, such as Alzheimer's disease and sleep comorbidities? As discussed in our concerns about the study of the astrocyte is the observation that astrocytes can become reactive extremely quickly. The term "reactive" was coined to express the notion that the astrocytic change is secondary to a primary pathology in neuronal function. However, this may not necessarily be the case. In epilepsy, astrocytes become reactive and lose the expression of glutamine synthetase, a key enzyme responsible for the conversation of glutamate to glutamine and the subsequent supply of a GABA precursor. Using viral strategies, it has been possible to induce gliosis in astrocytes. Murine-transduced astrocytes lose glutamine synthetase expression, like their human counterparts in medial temporal lobe epilepsy, which subsequently leads to a substantial deficit in GABAergic inhibition. As a consequence, preparations are hyperexcitable (Ortinski et al. 2010). Although this does not mean that epilepsy is caused by reactive astrocytes, it points to the potential for primary dysfunctions in astrocyte signaling to lead to changes in neuronal and consequently brain function.

Sleep disorders are comorbid with numerous disorders of the brain including depression, schizophrenia, Alzheimer's, and Parkinson's disease, to name a few. Additionally, sleep deprivation can lead to a reduction in the threshold for seizures. Given the importance of the astrocyte in modulating sleep-related processes, there is an exciting period ahead in which the introduction of newly refined molecular genetic approaches, together with animal models of diseases, will offer new insights into the roles of astrocytes in brain dysfunction.

\section{CONCLUSION}

Over the past 20 years, we have come a long way since the initial discoveries that astrocytic $\mathrm{Ca}^{2+}$ signals can impact neurons. During this period, 
members of the field have not always agreed about experimental design and interpretation, but what is clear is that we have made tremendous strides toward appreciating important roles for these dynamic glial cells in brain function. To be poised after only 20 years to make insights into how the astrocyte contributes to brain dysfunction is exciting and has the potential to offer new insights that might be translated into new treatments for at least some of these disorders.

\section{ACKNOWLEDGMENTS}

The authors are grateful to Takahiro Takano for assistance in generating the graphic used in Figure 1.

\section{REFERENCES}

Agulhon C, Fiacco TA, McCarthy KD. 2010. Hippocampal short- and long-term plasticity are not modulated by astrocyte $\mathrm{Ca}^{2+}$ signaling. Science 327: 1250-1254.

Allen NJ, Barres BA. 2005. Signaling between glia and neurons: Focus on synaptic plasticity. Curr Opin Neurobiol 15: $542-548$.

Araque A, Sanzgiri RP, Parpura V, Haydon PG. 1998. Calcium elevation in astrocytes causes an NMDA receptordependent increase in the frequency of miniature synaptic currents in cultured hippocampal neurons. J Neurosci 18: $6822-6829$.

Araque A, Parpura V, Sanzgiri RP, Haydon PG. 1999. Tripartite synapses: Glia, the unacknowledged partner. Trends Neurosci 22: 208-215.

Bekar L, Libionka W, Tian GF, Xu Q, Torres A, Wang X, Lovatt D, Williams E, Takano T, Schnermann J, et al. 2008a. Adenosine is crucial for deep brain stimulationmediated attenuation of tremor. Nat Med 14: 75-80.

Bekar LK, He W, Nedergaard M. 2008b. Locus coeruleus $\alpha$-adrenergic-mediated activation of cortical astrocytes in vivo. Cereb Cortex 18: 2789-2795.

Bekar LK, Wei HS, Nedergaard M. 2012. The locus coeruleus-norepinephrine network optimizes coupling of cerebral blood volume with oxygen demand. J Cereb Blood Flow Metab 32: 2135-2145.

Blutstein T, Haydon PG. 2013. The importance of astrocytederived purines in the modulation of sleep. Glia 61: 129139.

Brocher S, Artola A, Singer W. 1992. Agonists of cholinergic and noradrenergic receptors facilitate synergistically the induction of long-term potentiation in slices of rat visual cortex. Brain Res 573: 27-36.

Callado LF, Stamford JA. 2000. Spatiotemporal interaction of $\alpha_{2}$ autoreceptors and noradrenaline transporters in the rat locus coeruleus: Implications for volume transmission. J Neurochem 74: 2350-2358.
Chen N, Sugihara H, Sharma J, Perea G, Petravicz J, Le C, Sur M. 2012. Nucleus basalis-enabled stimulus-specific plasticity in the visual cortex is mediated by astrocytes. Proc Natl Acad Sci 109: E2832-E2841.

Chever O, Djukic B, McCarthy KD, Amzica F. 2010. Implication of Kir4.1 channel in excess potassium clearance: An in vivo study on anesthetized glial-conditional Kir4.1 knock-out mice. J Neurosci 30: 15769-15777.

Chung WS, Barres BA. 2012. The role of glial cells in synapse elimination. Curr Opin Neurobiol 22: 438-445.

Clasadonte J, Dong J, Hines DJ, Haydon PG. 2013. Astrocyte control of synaptic NMDA receptors contributes to the progressive development of temporal lobe epilepsy. Proc Natl Acad Sci 110: 17540-17545.

Cohen Z, Molinatti G, Hamel E. 1997. Astroglial and vascular interactions of noradrenaline terminals in the rat cerebral cortex. J Cereb Blood Flow Metab 17: 894-904.

Cornell-Bell AH, Thomas PG, Smith SJ. 1990. The excitatory neurotransmitter glutamate causes filopodia formation in cultured hippocampal astrocytes. Glia 3: 322 334.

Cragg SJ, Nicholson C, Kume-Kick J, Tao L, Rice ME. 2001. Dopamine-mediated volume transmission in midbrain is regulated by distinct extracellular geometry and uptake. $J$ Neurophysiol 85: 1761-1771.

D'Ambrosio R, Gordon DS, Winn HR. 2002. Differential role of KIR channel and $\mathrm{Na}^{+} / \mathrm{K}^{+}$-pump in the regulation of extracellular $\mathrm{K}^{+}$in rat hippocampus. J Neurophysiol 87: 87-102.

Ding F, O’Donnell J, Thrane AS, Zeppenfeld D, Kang H, Xie L, Wang F, Nedergaard M. 2013. $\alpha 1$-Adrenergic receptors mediate coordinated $\mathrm{Ca}^{2+}$ signaling of cortical astrocytes in awake, behaving mice. Cell Calcium 54: 387-394.

Dombeck DA, Khabbaz AN, Collman F, Adelman TL, Tank DW. 2007. Imaging large-scale neural activity with cellular resolution in awake, mobile mice. Neuron 56: 43-57.

Fellin T, Pascual O, Gobbo S, Pozzan T, Haydon PG, Carmignoto G. 2004. Neuronal synchrony mediated by astrocytic glutamate through activation of extrasynaptic NMDA receptors. Neuron 43: 729-743.

Fiacco TA, McCarthy KD. 2004. Intracellular astrocyte calcium waves in situ increase the frequency of spontaneous AMPA receptor currents in CA1 pyramidal neurons. $J$ Neurosci 24: 722-732.

Gurden H, Uchida N, Mainen ZF. 2006. Sensory-evoked intrinsic optical signals in the olfactory bulb are coupled to glutamate release and uptake. Neuron 52: 335-345.

Halassa MM, Florian C, Fellin T, Munoz JR, Lee SY, Abel T, Haydon PG, Frank MG. 2009. Astrocytic modulation of sleep homeostasis and cognitive consequences of sleep loss. Neuron 61: 213-219.

Han X, Chen M, Wang F, Windrem M, Wang S, Shanz S, Xu Q, Oberheim NA, Bekar L, Betstadt S, et al. 2013. Forebrain engraftment by human glial progenitor cells enhances synaptic plasticity and learning in adult mice. Cell Stem Cell 12: 342-353.

Hansen AJ, Lund-Andersen H, Crone C. 1977. $\mathrm{K}^{+}$-permeability of the blood-brain barrier, investigated by aid of a $\mathrm{K}^{+}$-sensitive microelectrode. Acta Physiol Scand 101: $438-445$. 
P.G. Haydon and M. Nedergaard

Henneberger C, Papouin T, Oliet SH, Rusakov DA. 2010 Long-term potentiation depends on release of D-serine from astrocytes. Nature 463: 232-236.

Hertz L. 1965. Possible role of neuroglia: A potassium-mediated neuronal-neuroglial-neuronal impulse transmission system. Nature 206: 1091-1094.

Hertz L, Chen Y, Gibbs ME, Zang P, Peng L. 2004. Astrocytic adrenoceptors: A major drug target in neurological and psychiatric disorders? Curr Drug Targets CNS Neurol Disord 3: 239-267.

Hoogland TM, Kuhn B, Gobel W, Huang W, Nakai J, Helmchen F, Flint J, Wang SS. 2009. Radially expanding transglial calcium waves in the intact cerebellum. Proc Natl Acad Sci 106: 3496-3501.

Hounsgaard J, Nicholson C. 1983. Potassium accumulation around individual purkinje cells in cerebellar slices from the guinea-pig. J Physiol 340: 359-388.

Huang S, Trevino M, He K, Ardiles A, Pasquale R, Guo Y, Palacios A, Huganir R, Kirkwood A. 2012. Pull-push neuromodulation of LTP and LTD enables bidirectional experience-induced synaptic scaling in visual cortex. Neuron 73: 497-510.

Iliff JJ, Wang M, Liao Y, Plogg BA, Peng W, Gundersen GA, Benveniste H, Vates GE, Deane R, Goldman SA, et al 2012. A paravascular pathway facilitates CSF flow through the brain parenchyma and the clearance of interstitial solutes, including amyloid $\beta$. Sci Transl Med 4: $147 \mathrm{ra111.}$

Izumi Y, Zorumski CF. 1999. Norepinephrine promotes long-term potentiation in the adult rat hippocampus in vitro. Synapse 31: 196-202.

Jourdain P, Bergersen LH, Bhaukaurally K, Bezzi P, Santello M, Domercq M, Matute C, Tonello F, Gundersen V, Volterra A. 2007. Glutamate exocytosis from astrocytes controls synaptic strength. Nat Neurosci 10: 331-339.

Kang J, Jiang L, Goldman SA, Nedergaard M. 1998. Astrocyte-mediated potentiation of inhibitory synaptic transmission. Nat Neurosci 1: 683-692.

Katsuki H, Izumi Y, Zorumski CF. 1997. Noradrenergic regulation of synaptic plasticity in the hippocampal CAl region. J Neurophysiol 77: 3013-3020.

Kuchibhotla KV, Lattarulo CR, Hyman BT, Bacskai BJ. 2009. Synchronous hyperactivity and intercellular calcium waves in astrocytes in Alzheimer mice. Science 323: 1211-1215.

Laalou FZ, de Vasconcelos AP, Oberling P, Jeltsch H, Cassel JC, Pain L. 2008. Involvement of the basal cholinergic forebrain in the mediation of general (propofol) anesthesia. Anesthesiology 108: 888-896.

Larsen BR, Assentoft M, Cotrina ML, Hua SZ, Nedergaard M, Kaila K, Voipio J, Macaulay N. 2014. Contributions of the $\mathrm{Na}^{+} / \mathrm{K}^{+}$-ATPase, NKCC1, and Kir4.1 to hippocampal $\mathrm{K}^{+}$clearance and volume responses. Glia 62: $608-$ 622.

Levitt P, Moore RY. 1978. Noradrenaline neuron innervation of the neocortex in the rat. Brain Res 139: 219-231.

Lind BL, Brazhe AR, Jessen SB, Tan FC, Lauritzen MJ. 2013. Rapid stimulus-evoked astrocyte $\mathrm{Ca}^{2+}$ elevations and hemodynamic responses in mouse somatosensory cortex in vivo. Proc Natl Acad Sci 110: E4678-E4687.
Lupfert C, Grell E, Pintschovius V, Apell HJ, Cornelius F, Clarke RJ. 2001. Rate limitation of the $\mathrm{Na}^{+}, \mathrm{K}^{+}$-ATPase pump cycle. Biophys J 81: 2069-2081.

Navarrete M, Araque A. 2008. Endocannabinoids mediate neuron-astrocyte communication. Neuron 57: 883-893.

Navarrete M, Perea G, Fernandez de Sevilla D, Gomez-Gonzalo M, Nunez A, Martin ED, Araque A. 2012. Astrocytes mediate in vivo cholinergic-induced synaptic plasticity. PLoS Biol 10: e1001259.

Nedergaard M. 1994. Direct signaling from astrocytes to neurons in cultures of mammalian brain cells. Science 263: $1768-1771$.

Nedergaard M, Verkhratsky A. 2012. Artifact versus reality-How astrocytes contribute to synaptic events. Glia 60: 1013-1023.

Nedergaard M, Ransom B, Goldman SA. 2003. New roles for astrocytes: Redefining the functional architecture of the brain. Trends Neurosci 26: 523-530.

Newman EA, Zahs KR. 1998. Modulation of neuronal activity by glial cells in the retina. J Neurosci 18: 4022-4028.

Nimmerjahn A, Mukamel EA, Schnitzer MJ. 2009. Motor behavior activates Bergmann glial networks. Neuron 62: $400-412$.

Orkand RK, Nicholls JG, Kuffler SW. 1966. Effect of nerve impulses on the membrane potential of glial cells in the central nervous system of amphibia. J Neurophysiol 29: 788-806.

Ortinski PI, Dong J, Mungenast A, Yue C, Takano H, Watson DJ, Haydon PG, Coulter DA. 2010. Selective induction of astrocytic gliosis generates deficits in neuronal inhibition. Nat Neurosci 13: 584-591.

Otmakhova NA, Lisman JE. 1996. D1/D5 dopamine receptor activation increases the magnitude of early long-term potentiation at CA1 hippocampal synapses. J Neurosci 16: $7478-7486$.

Parpura V, Verkhratsky A. 2012. Neuroglia at the crossroads of homoeostasis, metabolism and signalling: Evolution of the concept. ASN Neuro 4: 201-205.

Parpura V, Basarsky TA, Liu F, Jeftinija K, Jeftinija S, Haydon PG. 1994. Glutamate-mediated astrocyte-neuron signalling. Nature 369: 744-747.

Pascual O, Casper KB, Kubera C, Zhang J, Revilla-Sanchez R, Sul JY, Takano H, Moss SJ, McCarthy K, Haydon PG. 2005. Astrocytic purinergic signaling coordinates synaptic networks. Science 310: 113-116.

Paspalas CD, Papadopoulos GC. 1996. Ultrastructural relationships between noradrenergic nerve fibers and nonneuronal elements in the rat cerebral cortex. Glia 17: 133-146.

Paukert M, Agarwal A, Cha J, Doze VA, Kang JU, Bergles DE. 2014. Norepinephrine controls astroglial responsiveness to local circuit activity. Neuron 82: 1263-1270.

Pellerin L, Magistretti PJ. 1997. Glutamate uptake stimulates $\mathrm{Na}^{+}, \mathrm{K}^{+}$-ATPase activity in astrocytes via activation of a distinct subunit highly sensitive to ouabain. J Neurochem 69: $2132-2137$.

Perea G, Araque A. 2007. Astrocytes potentiate transmitter release at single hippocampal synapses. Science 317: 1083-1086.

Poskanzer KE, Yuste R. 2011. Astrocytic regulation of cortical UP states. Proc Natl Acad Sci 108: 18453-18458. 
Rangroo Thrane V, Thrane AS, Wang F, Cotrina ML, Smith NA, Chen M, Xu Q, Kang N, Fujita T, Nagelhus EA, et al. 2013. Ammonia triggers neuronal disinhibition and seizures by impairing astrocyte potassium buffering. Nat Med 19: 1643-1648.

Robitaille R. 1998. Modulation of synaptic efficacy and synaptic depression by glial cells at the frog neuromuscular junction. Neuron 21: 847-855.

Sano T, Kim YJ, Oshima E, Shimizu C, Kiyonari H, Abe T, Higashi H, Yamada K, Hirabayashi Y. 2011. Comparative characterization of GPRC5B and GPRC5CLacZ knockin mice; behavioral abnormalities in GPRC5B-deficient mice. Biochem Biophys Res Commun 412: 460-465.

Schmitt LI, Sims RE, Dale N, Haydon PG. 2012. Wakefulness affects synaptic and network activity by increasing extracellular astrocyte-derived adenosine. J Neurosci 32: 4417-4425.

Schummers J, Yu H, Sur M. 2008. Tuned responses of astrocytes and their influence on hemodynamic signals in the visual cortex. Science 320: 1638-1643.

Seifert G, Huttmann K, Binder DK, Hartmann C, Wyczynski A, Neusch C, Steinhauser C. 2009. Analysis of astroglial $\mathrm{K}^{+}$channel expression in the developing hippocampus reveals a predominant role of the Kir4.1 subunit. $J$ Neurosci 29: 7474-7488.

Shigetomi E, Bushong EA, Haustein MD, Tong X, JacksonWeaver O, Kracun S, Xu J, Sofroniew MV, Ellisman MH, Khakh BS. 2013. Imaging calcium microdomains within entire astrocyte territories and endfeet with GCaMPs expressed using adeno-associated viruses. J Gen Physiol 141: 633-647.

Stellwagen D, Malenka RC. 2006. Synaptic scaling mediated by glial TNF- $\alpha$. Nature 440: 1054-1059.

Sun W, McConnell E, Pare JF, Xu Q, Chen M, Peng W, Lovatt D, Han X, Smith Y, Nedergaard M. 2013. Glutamatedependent neuroglial calcium signaling differs between young and adult brain. Science 339: 197-200.

Takano T, Han X, Deane R, Zlokovic B, Nedergaard M. 2007. Two-photon imaging of astrocytic $\mathrm{Ca}^{2+}$ signaling and the microvasculature in experimental mice models of Alzheimer's disease. Ann NY Acad Sci 1097: 40-50.

Takano T, He W, Han X, Wang F, Xu Q, Wang X, Oberheim Bush NA, Cruz N, Dienel GA, Nedergaard M. 2014. Rapid manifestation of reactive astrogliosis in acute hippocampal brain slices. Glia 62: 78-95.

Takata N, Mishima T, Hisatsune C, Nagai T, Ebisui E, Mikoshiba K, Hirase H. 2011. Astrocyte calcium signaling transforms cholinergic modulation to cortical plasticity in vivo. J Neurosci 31: 18155-18165.
How Do Astrocytes Participate in Neural Plasticity

Thrane AS, Rangroo Thrane V, Zeppenfeld D, Lou N, Xu Q, Nagelhus EA, Nedergaard M. 2012. General anesthesia selectively disrupts astrocyte calcium signaling in the awake mouse cortex. Proc Natl Acad Sci 109: 1897418979.

Tomita H, Ziegler ME, Kim HB, Evans SJ, Choudary PV, Li JZ, Meng F, Dai M, Myers RM, Neal CR, et al. 2013. G protein-linked signaling pathways in bipolar and major depressive disorders. Front Genet 4: 297.

Traynelis SF, Dingledine R. 1988. Potassium-induced spontaneous electrographic seizures in the rat hippocampal slice. J Neurophysiol 59: 259-276.

Ullian EM, Christopherson KS, Barres BA. 2004. Role for glia in synaptogenesis. Glia 47: 209-216.

Verkhratsky A, Rodriguez JJ, Parpura V. 2012. Calcium signalling in astroglia. Mol Cell Endocrinol 353: 45-56.

Wallraff A, Kohling R, Heinemann U, Theis M, Willecke K, Steinhauser C. 2006. The impact of astrocytic gap junctional coupling on potassium buffering in the hippocampus. J Neurosci 26: $5438-5447$.

Walz W. 2000. Role of astrocytes in the clearance of excess extracellular potassium. Neurochem Int 36: 291-300.

Wang X, Lou N, Xu Q, Tian GF, Peng WG, Han X, Kang J, Takano T, Nedergaard M. 2006. Astrocytic $\mathrm{Ca}^{2+}$ signaling evoked by sensory stimulation in vivo. Nat Neurosci 9 : $816-823$.

Wang X, Takano T, Nedergaard M. 2009. Astrocytic calcium signaling: Mechanism and implications for functional brain imaging. Methods Mol Biol 489: 93-109.

Wang F, Smith NA, Xu Q, Fujita T, Baba A, Matsuda T, Takano T, Bekar L, Nedergaard M. 2012a. Astrocytes modulate neural network activity by $\mathrm{Ca}^{2+}$-dependent uptake of extracellular $\mathrm{K}^{+}$. Sci Signal 5: ra26.

Wang F, Xu Q, Wang W, Takano T, Nedergaard M. 2012b. Bergmann glia modulate cerebellar Purkinje cell bistability via $\mathrm{Ca}^{2+}$-dependent $\mathrm{K}^{+}$uptake. Proc Natl Acad Sci 109: 7911-7916.

Wang F, Smith NA, Xu Q, Goldman S, Peng W, Huang JH, Takano T, Nedergaard M. 2013. Photolysis of caged $\mathrm{Ca}^{2+}$ but not receptor-mediated $\mathrm{Ca}^{2+}$ signaling triggers astrocytic glutamate release. J Neurosci 33: 17404-17412.

Xie L, Kang H, Xu Q, Chen MJ, Liao Y, Thiyagarajan M, O'Donnell J, Christensen DJ, Nicholson C, Iliff JJ, et al. 2013. Sleep drives metabolite clearance from the adult brain. Science 342: 373-377.

Xu HT, Pan F, Yang G, Gan WB. 2007. Choice of cranial window type for in vivo imaging affects dendritic spine turnover in the cortex. Nat Neurosci 10: 549-551. 


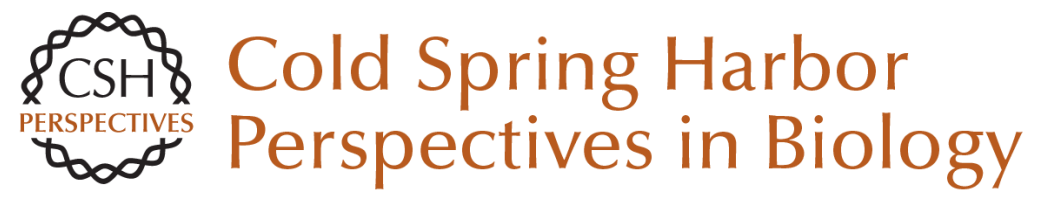

\section{How Do Astrocytes Participate in Neural Plasticity?}

Philip G. Haydon and Maiken Nedergaard

Cold Spring Harb Perspect Biol 2015; doi: 10.1101/cshperspect.a020438 originally published online December 11, 2014

\section{Subject Collection Glia}

The Nodes of Ranvier: Molecular Assembly and Maintenance

Matthew N. Rasband and Elior Peles

Microglia in Health and Disease

Richard M. Ransohoff and Joseph El Khoury

The Astrocyte: Powerhouse and Recycling Center Bruno Weber and L. Felipe Barros

Microglia Function in Central Nervous System

Development and Plasticity

Dorothy P. Schafer and Beth Stevens

Transcriptional and Epigenetic Regulation of Oligodendrocyte Development and Myelination in the Central Nervous System

Ben Emery and Q. Richard Lu

Origin of Microglia: Current Concepts and Past

Controversies

Florent Ginhoux and Marco Prinz

Glia Disease and Repair--Remyelination

Robin J.M. Franklin and Steven A. Goldman

Astrocytes in Neurodegenerative Disease

Hemali Phatnani and Tom Maniatis
Oligodendrocyte Development and Plasticity Dwight E. Bergles and William D. Richardson

Oligodendrocytes: Myelination and Axonal

Support Mikael Simons and Klaus-Armin Nave

Drosophila Central Nervous System Glia Marc R. Freeman

Perisynaptic Schwann Cells at the Neuromuscular

Synapse: Adaptable, Multitasking Glial Cells Chien-Ping Ko and Richard Robitaille

Astrocytes Control Synapse Formation, Function, and Elimination Won-Suk Chung, Nicola J. Allen and Cagla Eroglu

Schwann Cell Myelination James L. Salzer

Schwann Cells: Development and Role in Nerve Repair

Kristján R. Jessen, Rhona Mirsky and Alison C. Lloyd

Perineurial Glia

Sarah Kucenas

For additional articles in this collection, see http://cshperspectives.cshlp.org/cgi/collection/

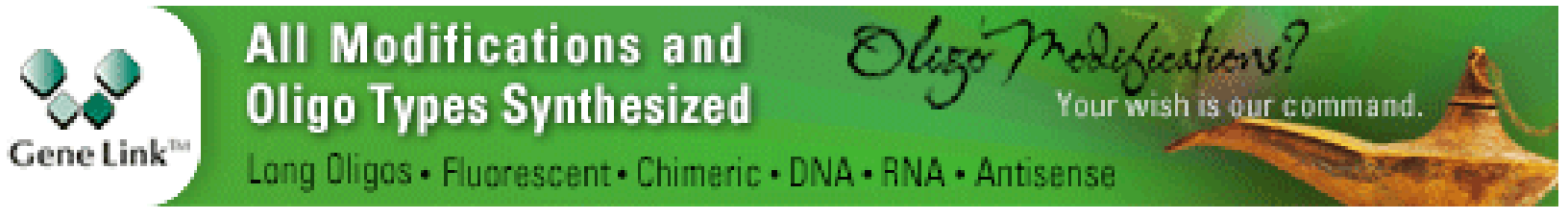

